\title{
Sepsis neonatal por Streptococcus Grupo B
}

\author{
MAGDALENA CRUZ O. ${ }^{1}$, ADRIANA DOREN V. ${ }^{1}$, \\ JOSÉ LUIS TAPIA I. ${ }^{2}$, FERNANDO ABARZÚA C. ${ }^{3}$ \\ 1. Interna de Medicina. \\ 2. Departamento Pediatría, Unidad de Neonatología. \\ 3. Departamento Obsteticia. \\ Escuela de Medicina, Pontificia Universidad Católica de Chile.
}

\begin{abstract}
\section{Group B Streptococcus neonatal sepsis: up-to-date}

Group B Streptococcus is one of the leading bacterias causing early onset neonatal sepsis. It constitutes an important factor of neonatal morbidity and mortality and high costs in health. Many strategies have been formulated to avoid vertical transmission from the colonized mother to the newborn, in an attempt to prevent infection of the infant. The most used nowadays is antibiotic prophylaxis given to the mother during labor, depending on the results of recto-vaginal culture taken during 35 to 37 weeks of gestation. This strategy has importantly diminished the prevalence of early onset neonatal sepsis by this agent, although there is still concern about the potential generation of antibiotic resistance and drug-induced adverse reactions in the mother. New techniques for prevention are being developed, such as vaccines against Streptococcus. In the newborn, infection caused by Streptococcus has a broad spectrum of clinical manifestations, like sepsis and meningitis which are the most frequent and lethal. Neurological sequelae are common among the survivors, so an early suspicion of disease must lead to a prompt antibiotic treatment.
\end{abstract}

(Key words: Sepsis, newborn, neonate, morbility, mortality).

Rev Chil Pediatr 2008; 79 (5): 462-470

\section{RESUMEN}

El Streptococcus grupo B (SGB) es uno de los principales agentes causales de sepsis neonatal precoz, siendo un importante factor de morbimortalidad neonatal y de costos en salud pública. Se han implementado múltiples estrategias para evitar la transmisión vertical desde la madre colonizada a su recién nacido, de modo de prevenir la infección de éste último. La más usada en la actualidad es la profilaxis antibiótica administrada a la madre en el momento del parto dependiendo del resultado de un cultivo perineal realizado entre las semanas 35 y 37 de gestación. Mediante esta estrategia se ha logrado disminuir de manera importante la incidencia de la sepsis neonatal por este agente, pero existen aprehensiones acerca de la

Trabajo recibido el 19 de junio de 2008, devuelto para corregir el 10 de julio de 2008, segunda versión el 01 de agosto de 2008, aceptado para publicación el 20 de agosto de 2008. 
posible generación de resistencia antibiótica o reacciones adversas a fármacos por parte de la madre. Por esto último, nuevas técnicas de prevención se encuentran en estudio, como las vacunas contra el SGB. En los recién nacidos la infección por Streptococcus agalactiae puede manifestarse de diversas maneras, siendo la sepsis y la meningitis las más frecuentes y mortales. El porcentaje de secuelas entre los sobrevivientes es elevado, por lo que ante la sospecha precoz de infección debe iniciarse tratamiento antibiótico a la brevedad.

(Palabras clave: sepsis, neonato, recién nacido, morbilidad, mortalidad).

Rev Chil Pediatr 2008; 79 (5): 462-470

\section{Generalidades}

La sepsis neonatal es una causa importante de morbimortalidad en los recién nacidos. Su incidencia varía entre regiones del mundo; en India y países vecinos se ha comunicado incidencia entre 1 a 16 en mil nacidos vivos ${ }^{1}$, mientras en Norteamérica su reporte varía entre 1 a 8 por mil $^{2}$. La letalidad también fluctúa según la población estudiada, reportándose valores que van desde menos del 5 al $70 \%{ }^{1,3}$.

La inmadurez del sistema inmune propia del recién nacido lo hace especialmente susceptible a este tipo de infecciones, las que tienden a diseminarse y generar cuadros clínicos graves. Esto se observa con mayor frecuencia en neonatos prematuros o de bajo peso ${ }^{4,5}$.

Según el momento de aparición de síntomas se clasifica la sepsis neonatal en precoz y tardía; la precoz se presenta dentro de las primeras 72 horas de vida y suele ser de origen connatal, y la segunda, que se considera fundamentalmente intrahospitalaria, se manifiesta pasadas las 72 horas de vida 4 .

Esta patología es causada principalmente por agentes bacterianos, y su transmisión se produce de madre a hijo por vía transplacentaria, ascendente $o$, principalmente, durante el trabajo de parto y parto. Hasta la década del 70 los principales agentes etiológicos eran los bacilos gram negativos, siendo posteriormente reemplazados por el Streptococcus agalactiae o Streptococcus grupo B (SGB), el cual llegó a explicar hasta más del 50\% de las sepsis preco$\operatorname{ces}^{6,7}$. La incidencia de sepsis precoz por SGB es variable con un rango entre 0,23 a 3,7 por mil nacidos vivos según la población estudiada; la incidencia de sepsis tardía por este germen va entre 0,3 a 1,8 por $\mathrm{mil}^{8}$.
La sepsis por $S$. Agalactiae se ha asociado a una mortalidad entre 5 y $20 \%$ en países desarrollados, y a un importante porcentaje de secuelas $(30 \%)$ entre los sobrevivientes ${ }^{9}$. Debido al alto impacto en la morbimortalidad neonatal por SGB, el tamizaje universal y profilaxis han sido propuestos por el Centro de Control de Enfermedades de Estados Unidos (CDC), justificando su implementación desde el punto de vista médico como económico ${ }^{10}$.

Gracias a los protocolos de prevención implementados basados en profilaxis antibiótica anteparto contra el SGB, a partir del año 2001 ha disminuido la importancia del Streptococcus agalactiae como agente etiológico de sepsis precoz, y en varias series recientes ha sido reemplazado en frecuencia por otras bacterias, siendo la Escherichia coli la que encabeza las nuevas casuísticas, volviendo así los bacilos gram negativos a ocupar los primeros lugares como en décadas anteriores ${ }^{9-11}$ (tabla 1). No se ha demostrado sin embargo, que las estrategias preventivas disminuyan la incidencia de sepsis tardía por SGB, como tampoco la denominada muy tardía sobre los 3 meses de edad; esto

Tabla 1. Etiología de sepsis precoz en dos períodos en el Hospital Clínico de la Universidad Católica de Chile ${ }^{9}$

\begin{tabular}{llc}
\hline & Etiología & \% \\
\hline 1995-1996 & Streptococcus agalactiae & 54 \\
& Escherichia coli & 0 \\
& Lysteria monocytogenes & 2 \\
$2001-2004$ & & \\
& Streptococcus agalactiae & 11 \\
& Escherichia coli & 22 \\
& Lysteria monocytogenes & 11 \\
\hline
\end{tabular}


debido a que la transmisión desde el canal de parto no juega un rol primordial en esta patología ${ }^{8}$.

\section{Streptococcus agalactiae y embarazo}

El S. Agalactiae es un diplococo gram positivo facultativo que presenta hemólisis completa al entrar en contacto con Agar sangre (hemólisis tipo $\beta$ ). Existen distintos serotipos, siendo el tipo III el más frecuentemente asociado a cultivos positivos en la madre $(26 \%)$ y enfermedad en el neonato $(64 \%)^{6}$.

Este germen coloniza de forma habitual el tracto gastrointestinal inferior y vagina, pudiendo ser dicha portación transitoria, intermitente o crónica. La adquisición o recolonización es frecuente en mujeres sexualmente activas. Varios estudios han demostrado que entre un 2 y un $34 \%$ de las embarazadas presentan colonización perineal durante el tercer trimestre ${ }^{12-14}$, siendo la tasa de portación reportada en Chile de un $20 \%{ }^{15}$. Esta colonización vaginal es la que finalmente se trasmite e infecta al feto durante el trabajo de parto. Uno a $2 \%$ de los recién nacidos de madres colonizadas desarrollarán sepsis9.

La portación perineal asintomática de las mujeres embarazadas se determina entre las 35 y 37 semanas de gestación, a través de un cultivo obtenido mediante un torulado de la región vaginal y anal, el cual se siembra en caldo de Todd-Hewitt enriquecido con ácido nalidíxico y gentamicina para aumentar la sensibilidad al eliminar agentes gram negativos. Luego, a las 24 horas se recultiva en agar sangre $^{16}$. El cultivo vaginal por sí sólo tendría una sensibilidad un $40 \%$ menor que la del obtenido por muestra rectovaginal; lo mismo ocurre si se realiza cultivo corriente y no en un medio selectivo ${ }^{17}$.

La sensibilidad y especificidad del cultivo rectovaginal a las 36 semanas de gestación para predecir colonización al momento del parto es de un 91 y $89 \%$ respectivamente ${ }^{18}$, en contraste con los cultivos obtenidos 6 o más semanas previo al parto, que muestran una sensibilidad y especificidad del 43 y $85 \%$ respectivamente para predecir este evento ${ }^{19}$. Es por esto que los cultivos realizados antes de las 5 semanas previas al nacimiento no son buenos predictores de la colonización al momento del parto, teniendo además en cuenta el gran número de partos que ocurren previo a las 34 semanas y a la posible recolonización. Es así como se han evaluado nuevas técnicas de pesquisa de $S$. Agalactiae perineal al momento del parto, siendo la más promisoria la reacción en cadena de polimerasa (PCR), que identificaría el germen en menos de 1 hora con una sensibilidad de 87 a $97 \%$ y especificidad de $95 \% 0^{20-21}$. Sin embargo, el costo beneficio de este método sigue en estudio, y aún no forma parte de las guías para tamizaje de SGB en mujeres embarazadas. Otras técnicas como el "Rapid Optical Inmunoassay-based Test" (OIA) y el test de latex, han demostrado una baja sensibilidad por lo que no serían útiles como métodos de tamizaje $22-23$.

Si bien el SGB suele ser asintomático en las madres, puede ser causante de infección del tracto urinario, endometritis, corioamnionitis, sepsis, y rara vez, meningitis ${ }^{24}$. También, se ha visto que existe una asociación importante entre la colonización materna por SGB y la ruptura prematura de membranas. Esto se debe a la capacidad de este microorganismo de producir fosfolipasas y proteasas, generar prostaglandinas e inducir respuesta inmune, que debilitan las membranas fetales ${ }^{25}$.

\section{Prevención}

La profilaxis para prevenir la sepsis por SGB en el recién nacido fue sugerida por primera vez en la década de los $70 \mathrm{~s}^{26}$. Debido a la elevada morbimortalidad asociada a la sepsis por este germen se han implementado medidas para evitar la transmisión vertical. En la década de los 80 s se demostró que el tratamiento intraparto de madres colonizadas por SGB reducía la tasa de contagio y sepsis en los recién nacidos ${ }^{27}$. El año 1992 la Academia Americana de Pediatría (AAP) recomendó hacer tamizaje a las embarazadas entre las 26 y 28 semanas de gestación a fin de pesquisar aquellas colonizadas con $S$. Agalactiae. Ese mismo año el Colegio Americano de Obstetricia y Ginecología 
(ACOG) recomendó el tamizaje basado en factores de riesgo, que incluía partos de pretérmino, antecedente de hijo previo con sepsis por SGB, bacteriuria por SGB en embarazo actual, rotura prematura de membranas de más de 18 horas, o fiebre intraparto (tabla 2). El año 1996 el CDC publicó las primeras guías de consenso para la prevención de esta patología, que se basaban en dar profilaxis antibiótica a aquellas embarazadas que presentaban factores de riesgo o un cultivo positivo para SGB, realizado entre las 35 y 37 semanas de gestación, bajo la premisa de que ambos protocolos serían igualmente costo-efectivos ${ }^{6}$. El resultado de la implementación de estas estrategias demostró una prevención de hasta un $68 \%$ de la sepsis por $S$. Agalactiae al utilizar el protocolo basado en

Tabla 2. Factores de riesgo para transmisión del SGB al recién nacido ${ }^{39}$

Corioamnionitis

Bacteriuria por Streptococcus agalactiae en embarazo actual

Colonización rectovaginal materna

Parte de pretérmino o RPO a edad gestacional menor a 37 semanas

Fiebre materna durante trabajo de parto $\left(\geq 38^{\circ} \mathrm{C}\right)$

Antecedente de recién nacido con sepsis precoz por Streptococcus agalactiae

Período de latencia entre RPO y parto prolongado ( $\geq 18$ horas) factores de riesgo; y usando el protocolo basado en cultivo, se logró una prevención del $89 \% 9,16,18,24,28-32$. Por este motivo, y teniendo en cuenta que hasta el $50 \%$ de las septicemias connatales se presentan en recién nacidos de término, hijos de madres colonizadas que no presentaban factores de riesgo ${ }^{6,18,33}$, el año 2002 el CDC modificó la guía promoviendo un nuevo enfoque que consistía en administrar profilaxis antibiótica a aquellas embarazadas que presentaran un cultivo positivo para SGB realizado entre las 35 y 37 semanas de gestación ${ }^{16,34}$. Según lo explicitado en dicha guía todas las mujeres embarazadas deben realizarse el cultivo a la edad gestacional establecida, estando liberadas de hacerlo sólo aquellas que hayan presentado bacteriuria por SGB en el embarazo actual o aquellas con antecedentes de un recién nacido previo con enfermedad invasiva por SGB, pues ellas recibirán indefectiblemente profilaxis intraparto. Bajo ésta guía reciben también antibióticos intraparto todas las pacientes que estén cursando trabajo de parto prematuro. Ésta ha sido considerada la estrategia más costo efectiva en la población de embarazadas de Estados Unidos $^{10}$. El protocolo basado en factores de riesgo sería recomendado sólo de no contar con un cultivo. Las indicaciones de profilaxis para SGB intraparto se resumen en la tabla 3.

En la actualidad aún existen organismos como el "Royal College of Obstetricians and Gynaecologists" ${ }^{135}$ que se basan en los factores

Tabla 3. Indicaciones de profilaxis intraparto para prevenir enfermedad perinatal por SGB siguiendo el tamizaje universal basado en cultivo rectovaginal realizado entre las 35 y 37 semanas de gestación de todas las mujeres embarazadas ${ }^{39}$

\section{Con indicación de profilaxis intraparto}

Bacteriuria por SGB en embarazo actual (no es necesario complementar con cultivo rectovaginal a las 35 a 37 semanas de gestación)

Colonización por SGB desconocida dentro de 6 semanas previas al parto asociado a:

- Edad gestacional menor a 37 semanas sin cesárea electiva

- RPO $\geq 18$ horas previo al parto

- Temperatura materna $\geq 38^{\circ} \mathrm{C}$ sin evidencia de corioamnionitis

Cultivo rectovaginal positivo para SGB tomado entre las 35 a

37 semanas de gestación

\section{Sin indicación de profilaxis intraparto}

Antecedente de embarazo previo con cultivo rectovaginal positivo

Cesárea electiva sin trabajo de parto ni rotura prematura de membranas (sin importar resultado cultivo SGB)

Cultivo rectovaginal tomado entre las 35 y 37 semanas de embarazo actual negativo para SGB (sin importar factores de riesgo) 
Tabla 4. Esquemas de profilaxis antibiótica para SGB intraparto ${ }^{6}$

\begin{tabular}{|c|c|}
\hline Recomendado & $\begin{array}{l}\text { Penicilina Sódica } 5 \text { millones UI endovenosos por una vez, y luego, 2,5 millones } \\
\text { cada } 4 \text { horas endovenosos hasta el parto }\end{array}$ \\
\hline Alternativa & $\begin{array}{l}\text { Ampicilina } 2 \mathrm{~g} \text { endovenosos por una vez, y luego, } 1 \mathrm{~g} \text { cada } 4 \text { horas endovenoso } \\
\text { hasta el parto }\end{array}$ \\
\hline Alergia a penicilina con riesgo de anafilaxis & $\begin{array}{l}\text { Clindamicina } 900 \text { mg cada } 8 \text { horas endovenosos hasta el parto, o, Eritromicina } \\
500 \text { mg cada } 6 \text { horas endovenosos hasta el parto, o, Vancomicina } 1 \mathrm{~g} \text { cada } 12 \\
\text { horas endovenoso hasta el parto si el germen es resistente a clindamicina y } \\
\text { eritromicina en el antibiograma informado junto con el cultivo. }\end{array}$ \\
\hline Alergia a penicilina sin riesgo de anafilaxis & $\begin{array}{l}\text { Cefazolina } 2 \mathrm{~g} \text { endovenosos, y luego } 1 \mathrm{~g} \text { cada } 8 \text { horas endovenoso hasta el } \\
\text { parto }\end{array}$ \\
\hline
\end{tabular}

de riesgo para la indicación de profilaxis intraparto para SGB, apoyándose en la premisa de que el tamizaje antenatal y tratamiento subsecuente no han demostrado una disminución real en la mortalidad neonatal general ${ }^{34}$ y a que podrían ser perjudiciales para la madre y el niño por potenciales efectos anafilácticos, interacciones con la medicación del trabajo de parto y la generación de resistencia antibiótica ${ }^{10,27,35}$. Teniendo en cuenta que bajo el protocolo de tamizaje entre un 30 a un $50 \%$ de las mujeres norteamericanas reciben profilaxis antibiótica, estos efectos podrían ser considerables ${ }^{36}$. Sin embargo, la prevalencia de sepsis por SGB en el Reino Unido es mucho menor incluso que la norteamericana por lo que probablemente sus estudios en cuanto a indicación de profilaxis no sean válidos para poblaciones con mayor incidencia.

La profilaxis consiste en la administración endovenosa de antibióticos siguiendo esquemas ya consensuados en la literatura (tabla 4$)^{16}$. La resistencia a penicilina o ampicilina no se ha observado en SGB, a diferencia de lo reportado con los esquemas que usan clindamicina o eritromicina, en los que se ha visto una resistencia de hasta un 15 y un $25 \%$, respectivamen$\mathrm{te}^{37}$. En nuestra experiencia existe resistencia a clindamicina en un $3,27 \%$ de los casos y un $2 \%$ a eritromicina, no existiendo resistencia a penicilina, ampicilina o cefazolina ${ }^{38}$. Estudios in vitro no muestran diferencia en la efectividad antiestreptocócica entre penicilina y ampicilina por lo cual algunos servicios emplean ésta última como antibiótico profiláctico. Sin embargo, el empleo de ampicilina se ha asociado a un incre- mento en la presencia de E. coli ampicilino resistente ${ }^{18}$. Debido a esto, la penicilina sigue siendo el antibiótico de elección para la profilaxis de Streptococcus agalactiae.

La administración de cualquiera de estos esquemas debe hacerse por vía endovenosa y deben ser recibidos por la madre al menos 4 horas antes del parto, para alcanzar concentraciones intraamnióticas adecuadas ${ }^{24,39}$.

\section{Streptococcus grupo B en el recién nacido}

La incidencia de sepsis por SGB ha disminuido considerablemente tras la implementación de guías de prevención del contagio vertical, llegando a cifras actuales de 0,23 a 1 en mil nacidos vivos en países desarrollados ${ }^{18,24}$. Lo que ha generado resultados dispares es si la incidencia de sepsis precoz globalmente disminuye con esta práctica. En nuestro centro encontramos una disminución de la sepsis precoz por SGB y globalmente comparando períodos pre y post introducción de profilaxis intraparto 9 . Sin embargo, en otras series no ocurre este fenómeno ${ }^{35}$.

Se ha considerado también la administración universal de una dosis de penicilina intramuscular a todos los recién nacidos o bien cuando se agregan factores de riesgo. Esta estrategia es también efectiva en disminuir la incidencia de sepsis precoz por $\mathrm{SGB}^{40}$. Sin embargo, ésta práctica no se ha implementado por la preocupación de crear una resistencia antibiótica a gérmenes adquiridos en infeccio- 
nes nosocomiales, además de que no hay consenso sobre su real efectividad ${ }^{6}$.

Debido a la importante morbimortalidad de esta patología, es necesario tener un alto índice de sospecha ante cualquier signo sugerente de infección sistémica en el recién nacido ${ }^{5}$. El algoritmo de manejo de neonatos nacidos de madres que recibieron profilaxis intraparto depende fundamentalmente de la capacidad del recién nacido de manifestar síntomas compatibles con enfermedad bacteriana, lo que dependerá de la edad gestacional; y del número de dosis de antibiótico profiláctico recibida por la embarazada $^{30}$ (figura 1). Los síntomas que deben hacernos sospechar sepsis en el recién nacido son altamente inespecíficos e incluyen inestabilidad térmica, succión débil, hipotonía, distensión abdominal o diarrea, dificultad respiratoria, palidez, petequias, hipoglicemia, alteración hemodinámica, e incluso convulsiones ${ }^{4}$. En un 88 a 94\% de los casos, los síntomas se manifiestan durante las primeras 24 horas de vida $^{6}$. La exposición a antibióticos profilácticos durante el trabajo de parto no mostró cambios en la clínica ni en el tiempo de aparición de los síntomas en los recién nacidos de término con infección por $\mathrm{SGB}^{41}$.
Así como la clínica es muy variada, también lo es el espectro de gravedad de esta infección, que va desde una celulitis a la muerte, pasando por cuadro de neumonia y meningitis, siendo la forma de presentación más frecuente la sepsis ${ }^{6}$.

El diagnóstico se confirma con hemocultivo y cultivo de líquido cefalorraquídeo, puesto que la meningitis ocurriría en un 5 a $10 \%$ de los $\operatorname{casos}^{8}$. Estos exámenes pueden no resultar positivos si la madre recibe antibiótico previo al parto. Es por esto que los antecedentes perinatales y la clínica son mandatarios a la hora de iniciar un tratamiento antibiótico empírico ${ }^{9,42}$.

Algunos elementos en el hemograma son sugerentes de infección sistémica en el recién nacido, por lo que sería una herramienta útil al momento del estudio. Se ha visto asociación entre sepsis por SGB y neutropenia, además de un aumento de las formas inmaduras en el recuento diferencial de glóbulos blancos ${ }^{4}$, no obstante puede ocurrir una sepsis neonatal por SGB con recuento leucocitario normal ${ }^{8}$. La proteína $\mathrm{C}$ reactiva no ha demostrado gran utilidad en el diagnóstico precoz de sepsis neonatal, debido a que su ascenso es tardío, por lo que su sensibilidad es baja en estadíos tempranos de la enfermedad, justamente cuando es más impe-

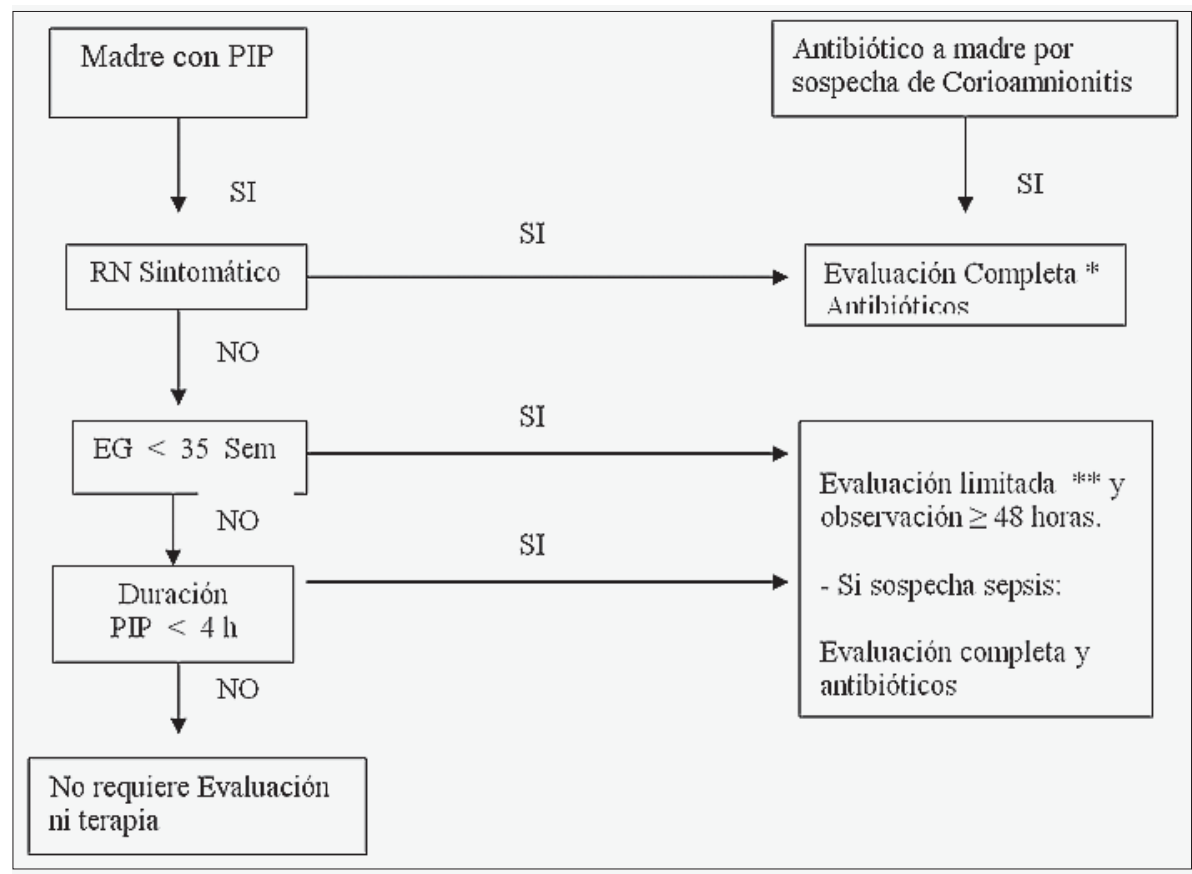

Figura 1. Algoritmo sugerido por el CDC para manejo de neonatos hijos de madres que recibieron profilaxis para $\mathrm{SGB}^{39}$. PIP $=$ Profilaxis intraparto. *Incluye hemograma, hemocultivo, radiografía de tórax ante signos respiratorios $\mathrm{y}$ punción lumbar sin signos de sepsis. **Incluye hemograma y hemocultivo. 
rioso instaurar una terapia empírica. Se ha estudiado la medición de procalcitonina para la detección de infección neonatal bacteriana, observándose que a mayores concentraciones mayor severidad del cuadro séptico, y que junto con ser más precoz arrojaría una superior sensibilidad y especificidad que la PCR. Sus desventajas serían que esta técnica posee una baja especificidad en el diagnóstico de sepsis en prematuros e hijos de madres diabéticas ${ }^{44}$.

Otra estrategia de detección rápida de infección por SGB en el neonato corresponde al uso de la reacción de aglutinación con látex en orina. Se ha visto que es esta técnica es útil como tamizaje por su alta sensibilidad, bajo costo y fácil implementación. Sin embargo, existe un número importante de falsos positivos $(20 \%)$ debido a la habitual contaminación de la muestra por contacto con piel del tracto urinario y perirectal ${ }^{45}$. Se describe su especial utilidad en aquellos recién nacidos que han recibido tratamiento antibiótico previo a la toma de cultivos o en los hijos de madres que recibieron profilaxis anteparto $^{46}$.

También se ha estudiado el uso de reacción en cadena de polimerasa para la detección rápida de colonización por SGB en el recién nacido hijo de madre sin cultivo de tamizaje al momento del parto, utilizando muestras de oído, nariz, recto y aspirado gástrico. Este método demostró gran sensibilidad y valor predictivo negativo en la pesquisa de portación neonatal, por lo cual permitiría discriminar el dar tratamiento o bien permitir un alta precoz en recién nacidos sin riesgo de infección por $\mathrm{SGB}^{43}$.

El tratamiento antibiótico empírico consiste en la administración de ampicilina asociada a un aminoglicosído por vía endovenosa, lo que cubriría tanto $S$. Agalactiae como otros patógenos habituales ${ }^{6}$. En nuestra unidad se utiliza ampicilina $100 \mathrm{mg}$ por kilo endovenoso cada 12 horas, más gentamicina $4 \mathrm{mg}$ por kilo endovenoso cada 24 horas en recién nacidos de término, dosis que va espaciándose en el tiempo mientras menor edad gestacional tenga el recién nacido ${ }^{4}$. En caso de no contar con ampicilina, se recomienda la terapia con penicilina asociada a gentamicina, siendo esta asociación igualmente efectiva que la de primera línea ${ }^{47}$.

Si se logra aislar S. Agalactiae en los hemo- cultivos realizados, se simplifica el esquema antibiótico, administrando penicilina sódica para completar 10 días de tratamiento. En cambio, si se confirma meningitis por SGB, se debe mantener el esquema biasociado con ampicilina y gentamicina hasta obtener cultivos de líquido cefalorraquídeo negativos, tras lo cual se continua sólo con penicilina sódica hasta completar un curso mínimo de 14 días 6 .

A pesar de que la sobrevida en sepsis por SGB ha mejorado en los últimos años, permanece baja en el grupo de recién nacidos prematuros. Se ha observado una sobrevida del $98 \%$ en los neonatos de término, del $90 \%$ en los nacidos entre las 34 y 36 semanas de gestación, y sólo del 70\% en los menores de 33 semanas $^{6}$. Dentro de los sobrevivientes se ha reportado hasta un 30\% de secuelas, siendo las neurológicas las más frecuentes, destacando la hidrocefalia, convulsiones, sordera, microcefalia, entre otros ${ }^{48}$.

\section{Perspectivas futuras}

Aún cuando las estrategias de prevención han resultado efectivas en reducir la incidencia de sepsis por SGB, hay que considerar que implican un costo no menor en exámenes y tratamientos, y existe el riesgo potencial de crear resistencia antibiótica y de emergencia de otras bacterias.

Con el fin de lograr una prevención más costo efectiva y a largo plazo, tanto en la madre como en el neonato, se ha planteado la inducción de respuesta inmune activa mediante el uso de vacunas. Éstas consisten en la administración de protein-polisacáridos conjugados de Streptococcus agalactiae serotipo III asociado a toxoide tetánico. Protocolos en fase I y II en adultos sanos, y en fase I en embarazadas, han demostrado seguridad e inmunogenicidad con resultados prometedores $\mathrm{s}^{6,21,30,49}$.

También se investiga el empleo de desinfectantes locales como clorhexidina aplicada en el canal de parto o para limpiar al recién nacido, de manera de reducir la transmisión vertical ${ }^{6}$. Hay evidencia sugerente de que esta medida disminuiría la morbimortalidad neonatal y las infecciones maternas postoperatorias ${ }^{40}$. Sin 
embargo, otros estudios han demostrado que esta medida no tendría mayor efecto en disminuir las infecciones neonatales por $\mathrm{SGB}^{50}$. Esta intervención resultaría más promisoria en países de escasos recursos ${ }^{6}$.

\section{Referencias}

1.- Stoll B, et al: The global impact of neonatal infection. Clin Perinat 1997; 24 (1): 1-15.

2.- Palazzi D, Klein JO, Baker CJ: Bacterial sepsis and meningitis. En Remington JS and Klein JO, editors: Infectious diseases of the fetus and newborn infant. $6^{\text {th }}$ edition, Philadelphia (PA): Elsevier Saunders 2006.

3.- Lukacs S, Schoendorf K, Schuchat A: Trends in sepsisrelated neonatal mortality in the United States, 19851998. Pediatr Infect Dis J 2004; 23: 599-603.

4.- Tapia JL, Perret $C$ : Infecciones Bacterianas. En Tapia JL, González A. Manual de Neonatología. III Edición, Santiago, Editorial Mediterráneo, año 2008.

5.- Gerdes JS: Diagnosis and management of bacterial infections in the neonate. Pediatr Clin North Am 2004; 51: 939-59.

6.- Gibbs RS, Schrag S, Schuchat A: Perinatal Infections due to Group B Streptococci. American College of Obstetricians and Gynaecologists 2004; 104, NO.5, part 1: 1062-76.

7.- Guzmán A, Abarzúa F, Belmar C, García P: Resultados de la aplicación del protocolo basado en screening para la búsqueda de Streptococcus agalactiae en el tercer trimestre del embarazo. Posible impacto sobre la sepsis neonatal precoz por este agente. Rev Chil Infectol 2001; 18: 187-92.

8.- Edwards MS, Nizet V, Baker CJ: Group B streptococcal infections. En Remington JS and Klein JO, editors. Infectious diseases of the fetus and newborn infant. $6^{\text {th }}$ edition, Philadelphia (PA): Elsevier Saunders 2006.

9.- Tapia JL, Reichard C, Saldías MI, et al: Sepsis Neonatal en la Era de Profilaxis Antimicrobiana Prenatal. Rev Chil Infect 2007; 24 (2): 111-6.

10.- Colbourn TE, Assenburg C, Bojke L, et al: Preventive strategies for group B streptococcal and other bacterial infections in early infancy: cost effectiveness and value of information analices. BMJ 2007 Sep 29; 335 (7621): 622-3.

11.- Bizarro M, Dembry LM, Baltimore R, Gallagher P: Changing Patterns in Neonatal Escherichia coli Sepsis and Ampicillin Resistance in the Era of Intrapartum Antibiotic Prophylaxis. Pediatrics 2008; 121 (4): 68996.

12.- Zaleznik D, Rench M, Platt R, Lee L, Baker J: Invasive disease due to group B Streptococcus in pregnant women and neonates for diverse population groups. Clin Infect Dis 2000; 30 (2): 276-81.

13.- Hafner E, Rosen A, Phillip K: Group B streptococci during pregnancy: Comparison of two screening and treatment protocols. Am J Obstet Gynecol 1998; 179 (3) Part 1: 677-81.

14.- Stoll B, Schuchat A: Maternal carriage of group B streptococci in developing countries. Pediatr Infect Dis J 1998; 1117: 499-503.

15.- Guzmán AM, Abarzúa F, Belmar C, García P: Resultados de la Aplicación del Protocolo basado en screening para la búsqueda de Streptococcus agalactiae en el Tercer Trimestre del Embarazo. Posible Impacto sobre la Sepsis Neonatal Precoz por este Agente. Rev Chil Infect 2001; 18 (3): 187-92.

16.- Center for Disease Control and Prevention: Prevention of perinatal group B streptococcal disease. MMWR Morbid Mortal Wkly Rep 2002; 51 (RR 11): 1-22.

17.- Philipson EH, Palermino DA, Robinson A: Enhanced antenatal detection of group B streptococcus colonization. Obstet Gynecol 1995; 85: 437-9.

18.- Benitz WE, Gould JB, Druzin ML: Risk factors for early-onset group B streptococcal sepsis: estimation of odds ratios by critical literature review. Pediatrics 1999; 103: e77.

19.- Yancey MK, Schuchat A, Brown LK, Ventura VL, Markenson GR: The accuracy of late antenatal screening cultures in predicting genital group B streptococcal colonization at delivery. Obstet Gynecol 1996; 88: 811-5.

20.- Bergeron N, Ke D, Menar D, et al: Rapid detection of group B Streptococci in pregnant women at delivery. NEJM 2000; 343 (3): 175-9.

21.- Larsen J, Sever J: Group B Streptcoccus and Prgenancy: a Review. Am J Obstet Gynecol 2008; 198 (4): 440-8.

22.- Abarzúa F, Zajer C, Guzmán AM, et al: Determinación de la Portación de Streptococcus agalactiae (Grupo B) en Embarazadas durante el Tercer Trimestre mediante Inmunoensayo. Rev Chil Obstet Ginecol 2002; 67 (4): 293-5.

23.- Nguyen TM, et al: Detection of group B streptococcus: comparison of an optic immunoassay with direct plating and broth enhanced culture methods. J Matern Fetal Med 1998; 7 (4): 172-6.

24.- American College of Obstetricians and Gynaecologists: ACOG Committee Opinion: number 279, December 2002. Prevention of early-onset group B streptococcal disease in newborns. Obstet Gynecol 2002; 100: 1405 12.

25.- Parry S, Strauss JF: Premature rupture of the fetal membranes. N Engl J Med 1998; 338: 663.

26.- Franciosi RA, Knostman JD, Zimmerman RA: Group B streptococcal neonatal and infant infections. J Pediatr 1973; 82: 707-18.

27.- Boyer KM, Gotoff SP: Prevention of early-onset neonatal group B streptococcal disease with selective intrapartum chemoprophylaxis. N Eng J Med 1986; 314: 1665-9.

28.- Schrag S, Zywicki S, Farley MM, et al: Group B streptococcal disease in the era of intrapartum antibiotic prophylaxis. N Engl J Med 2000; 342: 1520.

29.- Platt JS, O’Brien WF: Group B streptococcus: 
prevention of early-onset neonatal sepsis. Obstet Gynecol Surv 2003; 58: 191-6.

30.- Committee on Infectious Diseases and Committee on Fetus and Newborn: Revised guidelines for prevention of early-onset group B streptococcal (GBS) infection. Pediatrics 1997; 99: 489-96.

31.- Benitz WE, Gould JB, Druzin ML: Preventing earlyonset group B streptococcal sepsis: strategy development using decision analysis. Pediatrics 1999; 103: e76.

32.- Schrag SJ, Zell ER, Lynfield R, et al, for the Active Bacterial Core Surveillance Team: A population-based comparison of strategies to prevent early-onset group $\mathrm{B}$ streptococcal disease in neonates. $\mathrm{N}$ Eng J Med 2002; 347: 233-9.

33.- Rouse DJ, Goldenberg RL, Cliver SP, Cutter GR, Mennemeyer ST, Fargason CA Jr: Strategies for prevention of early onset neonatal group B streptococcal sepsis: A decision analysis. Obstet Gynecol 1994; 83: 483-93.

34.- Smaill F: Intrapartum antibiotics for group B streptococcal colonization. Cochrane Database of Systematic Reviews 1999; (3): 1-5.

35.- Royal College of Obstetricians and Gynaecologists: Guideline No. 36, November 2003.

36.- Kenyon SL, Taylor DJ, Tarnow-Mordi W: Broadspectrum antibiotics for preterm, prelabour ruptura of fetal membranes: ORACLE Collaborative Group. Lancet 2001; 357: 979-88.

37.- Pearlman $M D$, Pierson $C L$, Faix $R G$ : Frequent Resistance of Clinical group B streptococci isolates to clindamycin and erythromycin. Obstet Gynecol 1998; 92: 258-61.

38.- Belmar C, Abarzúa F, Becker J, Guzmán A, García $P$, Oyarzún E: Estudio de sensibilidad antimicrobiana de 183 cepas de Streptococcus agalactiae aisladas en región vagino-perineal de embarazadas en el tercer trimestre. Rev Chil Obstet Ginecol 2002; 67: 106-9.

39.- Schrag S, Gorwitz R, Fultz-Butts K, Schuchat A: Prevention of perinatal group B streptococcal disease. Revised Guidelines from CDC. MMWR Recomm Rep 2002 (rr-11): 1-22.
40.- Schrag S, Schuchat A: Prevention of neonatal sepsis. Clin Perinatol 2005; 32: 601-15.

41.- Bromberger P, Lawrence J, Braun D, Saunders B, Contreras $R$, Petitti D: The influence of intrapartum antibiotics on the clinical spectrum of early onset group B streptococcal infection in term infants. Pediatrics 2000; 106 (2): 244-50.

42.- Apgar BS, Greenberg G, Yen G: Prevention of Group B streptococcal Disease in the newborn. American Family Physician 2005; 71 (5): 903-10.

43.- Natarajan $G$, Jhonson $Y$, Zhang F, Chen KM, Worsha $M J$ : Real time polymerase chain reaction for the rapid detection of group B streptococcal colonization in neonates. Pediatrics 2006; 118 (1): 14-22.

44.- Koskenvuo MM, Irjala K, Kinnala A, Ruuskanen O, Kero P: Value of monitoring serum procalcitonin in neonates at risk of infection. Eur J Clin Microbiol Infect Dis 2003; 22: 377-8.

45.- Rench MA, Metzger TG, Baker CJ: Detection of group B streptococcal antigen in body fluids by a latexcoupled monoclonal antibody assay. J Clin Microbiol 1984; 20 (5): 852-4.

46.- Greenberg DN, Ascher DP, Yoder BA, Hensley DM, Heiman HS, Keith III JF: Sensitivity and specificity of rapid diagnostic tests for detection of group B streptococcal antigen in bacteremic neonates. J Clin Microbiol 1995; 33 (1): 193-8.

47.- Metsvaht T, Padari H, Lang K, Lutsar I: Penicillin plus gentamicin versus Ampicillin plus gentamicin in the empiric treatment of early neonatal sepsis. $16^{\text {th }}$ European Congress of Clinical Microbiology and Infectious Diseases. Nice, France, April 1-4 2006.

48.- Fluegge K, Siedler A, Heinrich B, et al: Incidents and clinical presentation of invasive neonatal group B streptococcal infections in Germany. Pediatrics 2006; 117 (6): 1139-45.

49.- Paoletti LC, Madoff LC: Vaccines to prevent neonatal GBS infection. Semin Neonatol 2002; 7: 315-23.

50.- Rouse DJ, Aut JC, et al: Clorhexidine vaginal irrigation for the prevention of peripartal infection: a placebocontrolled randomized clinical trial. Am J Obstet Gynecol 1997; (176): 617-22. 